\title{
chaperer Changing Generations I: Children, Adolescents and Young People
}

\author{
Arnon Bentovim
}

\section{Introduction}

This chapter will review the societal and political context in which there was an evolution of approaches to address the mental health needs of children and young people. ${ }^{1}$ In the $1960 \mathrm{~s}$ and 1970s, stimulated by socio-cultural changes, new innovations in therapeutic approaches were introduced, including family therapy and cognitive behavioural therapy (CBT). The first major longitudinal and epidemiological research studies were carried out. In the 1970s and 1980s, there were challenges to the state's capacity to deal with a variety of social problems and various forms of child maltreatment were identified. A national multidisciplinary assessment and management framework was introduced aimed at protecting the child, supporting families and developing appropriate treatment initiatives. In the 1990s and 2000s, further interventions were developed to reverse the impact of social exclusion for example, Sure Start. There was a consolidation of practice, including both general and highly specialised services, and further development in research and training.

\section{The Societal Context: 1960s and 1970s}

During the post-war years, the promotion of national growth and well-being had been a priority with the establishment of the National Health Service (NHS) and the welfare state. ${ }^{2}$ Then, as a result of post-war fertility and the baby boom, demographics tilted towards youth; by the 1960s and 1970s, fuelled by the 'youth culture', there was a marked change towards an anti-establishment cultural phenomenon in the Western world. Disaffected young people rebelled against the Vietnam War. Socially progressive values grew, encompassing feminism, women in leadership roles, environmentalism, civil rights, a sexual revolution relaxing social taboos, easier birth control, repeal of sexist laws and gay liberation. There were also increasing stresses, family break-ups, divorce and single parenthood.

\section{Traditions: Child and Adolescent Psychiatry in the 1960s and 1970s}

\section{The Child Guidance Movement}

The child guidance clinic model was established in the 1930s: the 'trinity' of a psychiatrist seeing the referred child, a social worker engaging with the mother and an educational psychologist testing the child and liaising with the school. ${ }^{3}$ Many child and adolescent psychiatrists underwent psychoanalytic training. Psychiatric social workers trained in casework skills and educational psychologists had a background in teaching. 
Regular sessions were offered to the child or young person, promoting an attachment through a child-centred approach, using play and artistic materials to encourage the expression of feelings. The approach gave the child the experience of an adult creating a warm, positive attachment and facilitated reflecting on their lives, sharing traumatic and stressful events and trying to make sense of their anxieties and depressed mood as well as managing behaviours, solving problems and finding solutions. Casework with mothers to support them in the challenging task of parenting provided an opportunity for mothers to reflect on their own experiences, current and historical stresses, and relationships, which were influencing their parenting. They were helped in managing their children's challenging behaviour as well as being emotionally responsive and understanding. The psychologist supported the child or young person in the educational context. By 1970, there were 367 clinics in the UK.

\section{Child Psychotherapy}

There was significant controversy in working therapeutically with children and young people. ${ }^{4}$ Anna Freud's approach at the Hampstead Clinic emphasised the supportive 'egostrengthening' role of the therapist and the use of play materials, games and activities to promote growth and resilience. Kleinian approaches at the Tavistock Clinic centred on the object-relations, transference and counter-transference interpretation of children's play and responses to the therapist in order to resolve early sources of anxiety and promote maturation.

Winnicott, a paediatrician and psychoanalyst who gained renown from his wartime broadcasts, supported an independent/'middle' group approach - illustrated through his demonstrations of 'squiggle' drawing encounters with children. The child and the therapist challenged each other to turn a shape into an image, thus reflecting experiences which could be built on as part of a creative encounter. Winnicott built on the notion of transitional space underpinning play and creativity (see also Chapter 15$).^{5}$

The Association of Child Psychotherapists, established in 1949, fostered different approaches and maintained a continuity of traditions of training in working intensively with children, adolescents and young people. Work developed with special populations of children - in residential and care contexts and with autistic spectrum disorders and learning/intellectual disability. Related creative forms of therapeutic work have developed play therapy, art and music therapy and educational therapies.

\section{Innovations: 1960s and 1970s}

\section{Developments of Family Therapy and Multidisciplinary Practice}

Although effective, the child guidance clinic model proved static and unresponsive to the changing societal dynamics. A striking development was the growth of family therapy. ${ }^{6}$ Bowlby introduced family meetings to reinforce individual therapy; Skynner, a group analyst, worked with the family as a group. A seminal paper by Bateson, 'The DoubleBind Theory of Schizophrenia', in 1962, asserted that disordered communication led to pathological outcomes. Children's mental health difficulties were triggered and maintained by pathological family interactions. Minuchin developed 'structural' approaches, working with family communications, boundaries and alliances aiming to alter interactions between family members and improve the functioning of the child. The model was transmitted widely by videos of therapeutic work, large-scale dramatic demonstrations and public media 
forums, an approach which contrasted vividly with traditional more private and reflective approaches.

Therapists were trained in experiential approaches such as 'moving family sculptures' and 'role play' to facilitate the development of skills and understanding. Live supervision of clinical work took place through one-way screens and electronic bugs in the ear. Despite reservations, there was an enthusiastic take-up of the approach. Child and adolescent psychiatrists, psychologists and social workers started working with families and collaborated to establish training, which led to the founding of the Association of Family Therapy in 1976, rebalancing the dynamics between the different professionals. Therapeutic skills could be developed and effective therapy delivered to children and their families by a range of professionals across health and social care as well as education.

\section{Developments in Cognitive Behavioural Therapy (CBT)}

CBT emerged as an amalgam of behavioural and cognitive theories of human behaviour. ${ }^{7}$ Behavioural therapy had been developed in the 1960s and included Patterson's parent-training model, introducing consistent approaches to managing challenging disruptive behaviour. An increased awareness of the role of cognition led to the transition to CBT in the 1970s. Internal thought processes (e.g. self-talk) began to be viewed as both targets and mechanisms of change, with an emphasis on improving cognitive skills linked with modifying behaviour. Selfinstruction emerged to teach impulsive children how to control their behaviour.

Psychological disorders were attributed to maladaptive cognitive processes, with psychological vulnerabilities developing as a result of early socialisation experiences within the family. Specific CBT approaches for children and young people incorporated parent training and the development of children's mastery over their own environment. Specific protocols emerged for the treatment of anxiety and depression, trauma-focused CBT and parent training. The Triple $\mathrm{P}$ and Incredible Years programmes have been widely adopted. CBT has become a well-established, online, self-guided approach, which is as effective as face-to-face treatments in appropriate circumstances.

\section{Developments in Research and Practice in Child and Adolescent Mental Health}

\section{Attachment}

Bowlby's 1951 review of maternal deprivation in Maternal Care and Mental Health had a significant influence on the development of research in the field. ${ }^{8}$ He highlighted the core role of maternal attachment for the secure development of the child. Psychoanalytic colleagues criticised his emphasising the role of real-life experiences rather than the inner world. Rutter praised positive consequences, for example parents staying with their children in hospital but echoed feminist criticisms that even brief daily maternal separations were assumed to be harmful. ${ }^{9}$ He observed that the controversy generated empirical research about children's development, family relationships and the importance of good-quality alternative care. The 'attachment' concept has played a key role in professional and public awareness about the care of children and the security and organisation of attachment and mental health and as a target for therapeutic work. 


\section{Research Methodologies, Assessment and Measurement}

Assessing and measuring the nature, extent and severity of mental health difficulties is an essential component of research and practice. ${ }^{10}$ Questionnaires, interviews and observational approaches help to identify the presence of disorders, including depressed mood, anxiety, traumatic responses, anti-social behavioural symptoms and concentration difficulties.

Longitudinal research identified cohorts of children at birth followed through to adulthood, establishing continuities of mental health disorders between childhood, adolescent and adult life, identifying harmful and protective influences on development. Following the development of children through to adulthood has also been a popular theme in TV documentaries.

The 1970 Isle of Wight Study, led by Rutter, ${ }^{11}$ was a key development in epidemiological research, demonstrating the value in screening whole populations and interviewing children, adolescents, young people and families. The epidemiological model has examined many influences on children and young people's development, including prenatal factors, smoking and alcohol misuse; family factors - parental mental health, neglect and abuse, separation and divorce; and community and school influences. This knowledge has influenced public health, preventative approaches, support for parenting and clinical practice.

Measures of family and parenting relationships include attachment quality and parenting capacity. The Multiaxial Approach to Diagnosis, introduced in 1975, provided a way to describe complexity - the nature of the presenting disorder, the level of intellectual functioning, medical factors and the psychosocial factors, including family characteristics. Assessing the effectiveness of therapeutic approaches in research and practice enhances professional and public awareness of the value of treatments.

\section{Specific Disorders of Emerging Public Interest}

Self-harming suicidal behaviour, anorexia nervosa, and other eating disorders are the main mental health conditions in young people which can lead to death. ${ }^{12}$ Widely publicised tragic cases of young people with talent and promise self-harming - cutting, over-dosing, killing themselves - led to demands for improved and accessible mental health services. Increasing numbers of young people were presenting with self-starvation, distorted body image and a fear of fatness, associated with obsessive self-control of eating and calorie counting. There is continuing debate about societal aspirations for an idealised slim body shape and young people identifying with models or dancers.

Autistic disorders and attention deficit hyperactivity disorder (ADHD) are key neurodevelopmental disorders. Rutter delineated autism as a separate, specific disorder with deficits in social skills, empathy, problems of speech and non-verbal behaviours as well as repetitive stereotyped behaviours. ${ }^{13}$ High-functioning individuals were identified with Asperger's syndrome and sometimes showed areas of abilities, talents and exceptional skills - for example, mathematical, musical and artistic, an interest fostered by films and TV series.

ADHD is a neurodevelopmental disorder with a classic pattern of short attention span, inattentiveness, hyperactivity, and impulsiveness, and is recognised in schools and families. ${ }^{14}$ Treatment with psychostimulants improved concentration and educational attainment and demands for treatment followed, evoking controversy about the potentially harmful effects of medication in general and on children's growth and development. 


\section{The Recognition of Child Maltreatment: 1970s and 1980s}

\section{The Battered Child}

A key to recognising child maltreatment was the publication in 1962 of Kempe and colleagues' highly influential paper 'The Battered-Child Syndrome'. ${ }^{15}$ Images of bruising and broken bones focused the thinking of child health practitioners worldwide. The sequence of identification in society of different forms of maltreatment followed:

- Physical abuse - burns, fractures and bruises; a child 'deserving punishment'

- Neglect and failure to thrive - unawareness of the needs of the child

- Emotional abuse - rejection and scapegoating

- Exposure to violence - domestic violence and abuse

- Sexual abuse - sexual interest and exploitation of the child and young person.

There was also the recognition that a rare unintended consequence of mothers staying with children in hospital was that, despite appearing loving and close, some came to be understood as seeking support through having a sick child. Symptoms could be falsified or exaggerated, resulting in factitious illness states - Munchausen's syndrome by proxy or nonaccidental poisoning. ${ }^{16}$

Epidemiological research revealed the extent of maltreatment, its under-reporting and the long-term impact on physical and mental health. ${ }^{17}$ Finkelhor described 'polyvictimisation', the exposure to multiple forms of maltreatment over childhood. ${ }^{18}$ As maltreatment can be defined as a criminal action, a social problem or a health disorder, a multidisciplinary response was advocated, led by social services. Practitioners from the police, health and social care and education were encouraged to 'Work Together' to recognise the signs of child maltreatment, carry out the necessary assessments, ensure the child or young person is protected though legal processes if necessary and provide intervention to help the child and family. This included appropriate treatment for complex parental mental health issues, including alcohol and substance abuse. Prosecution was reserved for the most serious injuries. There was increasing awareness of the intergenerational traumatic impact on children's health and development and the need to provide a range of therapeutic interventions.

\section{Recognition of Sexual Abuse}

Our survey of professionals working with children in 1981 revealed that the sexual abuse of children was recognised as a crime not a focus of child protection, ${ }^{19}$ an attitude which has persisted. Following wider publication on the issue, many individuals who had suffered sexual abuse and exploitation in silence came forward to speak about their persisting traumatic experiences. There is continuing evidence about the pervasive impact of harmful sexual exploitation of vulnerable children by individuals with power - in families, communities, churches, schools, sports and entertainment.

A family and group treatment programme was established at Great Ormond Street Children's Hospital in $1981,{ }^{20}$ providing diagnosis and treatment for children, male and female victims, young people, protective mothers and abusive young people and parents. A rehabilitation approach based on family systemic principles was initiated, including, where possible, individuals in prison, who could take responsibility directly for abusive behaviour, albeit with stringent safeguards. A BBC Horizon documentary 'Prisoners of 
Incest' in 1984 demonstrated the approach but was controversial from feminist perspectives that raised concerns about an inappropriate accommodation to perpetrators, who were at risk of continuing abusive behaviour.

\section{Public Recognition of Maltreatment}

The reality of child maltreatment was brought home by the tragic case in 1974 of Maria Colwell, a child subjected to extensive physical abuse. ${ }^{21}$ This was the first in a series of thirty public inquiries into serious child maltreatment, with the most recent being Victoria Climbié in 2000 and 'Baby P' in 2009. There was extensive media coverage, detailed accounts about what had gone wrong and questioning of the current state of policy and practice. Social work professionals who had been made responsible for child protection were named, vilified and harshly criticised for accommodating to parents, failing to recognise and not using their statutory powers to protect children.

The secrecy and threat associated with sexual abuse make diagnosis through interviews and physical examination complex and challenging. In 1986, the paediatricians Hobbs and Wynne described a series of sex rings in a northern city and the criteria for diagnosis of boys and girls who had sustained anal abuse. ${ }^{22}$ The Cleveland affair in the summer of 1987 focused on the work of two paediatricians and a social worker. ${ }^{23}$ More than 100 children had been removed from their families over a short period, based in part on physical findings associated with possible sexual abuse. The findings were fiercely criticised as dubious in the media and parliament. The widely reported inquiry that followed highlighted the risk of professional intervention on questionable grounds and criticised the 'over-enthusiastic' use of medical science. The inquiry supported the rights of parents, in practice, undermining the attempts of practitioners to find ways to amplify the voice of the child who had been silenced. Our facilitative approach to interviews using anatomically correct dolls was also challenged.

\section{Social Context: The Children Act}

Implicit in the narrative of failure, incompetence and 'over-zealous' approaches to protect children were a criticism of social welfare approaches. The 1980 s were characterised generally by an increasing disillusionment with the ability of the social democratic state to manage the economy and overcome a range of social problems. There was a rise in violence and a decline in social discipline. An alternative, individualised concept of relationships and market forces was advanced, aimed at shrinking the state. The family was seen as a predominantly private domain, excluding the state unless violence was being perpetrated.

This thinking underpinned the establishment of the Children Act 1989. ${ }^{24}$ The Act provided a legal framework which emphasised the importance of providing support for families and established criteria for a child being at risk of 'significant harm' to justify removal from a parent's care. Mental health professionals played a key role in helping the courts understand the risks, the prospects for rehabilitation, the provision of treatment services and the possibility of the need for alternative care or, ultimately, adoption.

In parallel, the United Nation's Convention on the Rights of the Child (1989) was established to ensure that services were provided to enable children to participate in society, to have a voice and to be protected from violence and exploitation. 


\section{Consolidation of Mental Health Services for Children, Adolescents and Young People: 1990s to 2010}

\section{Social Policy Context}

This period was marked by the last phase of Thatcherism, which extended market rationalities and focused on the individual rather than governing through society. ${ }^{25}$ New Labour from 1997 to 2009 espoused the 'third way', combining individualism and egalitarianism and thus reconciling apparently conflicting cultural projects: personal self-realisation and rights to autonomy; and membership and community. Initiatives focused on reversing social exclusion, stressing the need for early intervention and prevention, including the Sure Start and Children's Fund programmes. Despite significant investment, there was no full-scale attempt to reduce social inequality, although more than a million children were lifted out of poverty. The final year of this period, following the financial crash, saw the reelection of a Conservative-Liberal Democrat coalition government destined to pursue a programme of austerity, a reduction in public services, shrinking of the state and a further drive towards the privatisation of public services.

\section{Development of Services}

By the 1990s, child and adolescent mental health had a higher profile in both the public and the professional worlds. More academic chairs and departments of child and adolescent psychiatry were established, and training and accreditation programmes were developed. Research developed across the fields, including in genetics, molecular biology and neurobiology (see also Chapter 16). ${ }^{26}$

A four-tiered framework of CAMHS (Children and Adolescent Mental Health Services) as a health service was established in 1995, replacing child guidance clinics:

Tier 1 Advice and treatment provided by practitioners working in a variety of settings in the community, in general practice, in schools and in agencies working with maltreated children - e.g. the NSPCC (National Society for the Prevention of Cruelty to Children).

Tier 2 Generic multidisciplinary teams - providing core community services for children, adolescents and young people.

Tier 3 Specialist multidisciplinary services.

Tier 4 Highly specialised services providing outpatient and inpatient care for young people presenting with early psychotic illness, eating disorders or displaying sexually harmful behaviour.

A highly specialised service that attracted much attention and controversy was the establishment of the Tavistock Gender Identity Development Service in $1989 .{ }^{27}$ Following rigorous assessments and therapeutic help, a young person's wish to transition and develop their gender identity could be facilitated through medical and psychological intervention. During the controversy, it was asserted on the one hand that, lacking maturity, the deeply held wishes of young people should not be supported until they reached adulthood; on the other hand that there should be respect for the emerging individuality and autonomy of the young person.

The NHS organisation NICE (the National Institute for Clinical Excellence, later renamed as the National Institute for Health and Care Excellence) was established in 
1999 and recommended the most effective approaches to help children and young people with mental health problems. The IAPT (Improving Access to Psychological Treatment) programme provided access to these effective therapies and was introduced to adult services in 2008 and children's services in $2011 .^{28}$ MindEd training was introduced to complement IAPT and to provide online training in emotional and behavioural 'first aid' and essential therapeutic skills.

One of the treatments recommended by NICE was the extensively researched CBT, with the risk that other modalities would be dismissed. Later research demonstrated that wellstructured family/systemic or psychodynamic approaches were equally effective. In addition, much research focused on single disorders. The reality is that comorbid disorders are the rule rather than the exception. An alternative has been the development of integrative approaches, bringing different modalities together. ${ }^{29}$ The common treatment element approach identified and categorised common features of treatments which can be integrated to meet complex needs, ${ }^{30}$ an approach we adopted to reduce the harmful effects of all forms of maltreatment. ${ }^{31}$

\section{Young Offenders Services}

Young Offenders Services were established in 1998, with special school, youth courts, residential care and young offender institutions. However, the age of criminal responsibility remained at ten years. The world's press had heard a blow-by-blow account of the killing of James Bulger by two vulnerable eleven-year-olds in 1993 in an adult court. Popular judgement was that the children were 'evil' and 'devious' and deserved to be in prison for life. Growing knowledge was ignored about the way the young person's brain matures and responds to earlier trauma, undermining their capacity for judgement and control of impulsivity.

Our follow-up study of sexually abused boys demonstrated that sexually harmful adolescent or adult behaviour was more likely if they had also witnessed violence and suffered rejection. ${ }^{32}$ Attempts to change the age of criminal responsibility have been firmly resisted. The aggressive behaviour of adolescents and young people has continued to be a societal and media preoccupation - with gangs, knife crimes, bullying and 'children who kill'.

\section{Developments in Child Protection: Trauma-Informed Care}

In 1988, in describing adverse childhood experiences (ACEs), Felitti and colleagues extended the concept of maltreatment to include household dysfunction and instability resulting from domestic violence; parental substance abuse; mental illness; imprisonment; and separation. ${ }^{33}$ They found that the more types of ACEs that individuals reported in their childhood (e.g. emotional, physical or sexual abuse; physical or emotional neglect; mother treated violently; household substance abuse or mental illness; incarcerated household member; and parental separation or divorce), the greater their risks of healthharming behaviours (e.g. smoking or sexual risk-taking) and both infectious and noncommunicable diseases (NCDs), including substance abuse, mental health problems and violent behaviour.

The Framework for the Assessment of Children in Need and Their Families, in 2000, broadened the approach and provided a model for practitioners across children's social care to describe the child's needs in the context of parenting, individual and community factors. We were commissioned to develop and provide training in evidence-based approaches to 
assessment, analysis and intervention. ${ }^{34}$ Trauma-informed care in the community was introduced in 2005, integrating policies, procedures and practices as well as identifying potential paths for recovery.

\section{The Internet: Beneficial and Harmful Influences}

The World Wide Web, launched in 1989-90, gained massive popularity in the mid-1990s and was a near-instant communication aid and way of registering knowledge and information. ${ }^{35}$ The development of online therapeutic work and training has grown. Young people embraced the Internet, using it for social networking, communicating, expanding their interests, enriching their lives, entertainment, gaming, connecting and learning. Important issues, including gender identification as male, female or transsexual, could be debated. The Internet gives a voice to children and young people and may provide informal support and advice about managing specific problems, for example self-harm and anorexia.

The harmful impact of the Internet has also dominated social discourse, including exposure to age-inappropriate material online, pornography, violence or hate speech. Child pornography is circulated on the Web, and children may be groomed into creating and circulating images of sexual activities. Perpetrators have falsified their identities and groomed young people as a way of meeting and exploiting them sexually. Self-harm, suicide or anorectic behaviour can be encouraged online. Children and young people can abuse each other by sexting (sending sexual images, thus risking blackmail), cyber-bullying, harassment, disclosure of personal information or threats of social exclusion may trigger self-harm and suicidal responses.

The issue of the safety and control of the Internet is a constant and continuing theme. Childline, established in 1986, currently receives multiple calls about abuse over the Internet. Offenders can be helped anonymously to break the addictive cycle through 'Stop it Now' ${ }^{36}$ Children, young people and parents can be helped to understand the beneficial and harmful risks associated with internet use.

\section{Conclusion}

In their masterly review of the history of child and adolescent mental health 1960-2010 Rutter and Stevenson concluded: 'there has been an amazing revolution in child and adolescent psychiatry ... As a consequence, the body of knowledge, and the range of therapeutic interventions have increased in a way that would have seemed scarcely conceivable 50 years ago.' 37 This review has confirmed these conclusions, focusing on the interface between society and mental health; promoting developments in therapeutic approaches and services to the community; and identifying and managing the pervasive and lifetime harmful impact of child maltreatment and adversity.

\section{Key Summary Points}

- From the 1960 s to the 1980 s, in parallel to societal changes from welfarism to the counterculture, the legacy of the child guidance movement and psychodynamic approaches gave way to more active, transparent and fast-moving therapies. Family/ systemic therapy involved the whole family and trained practitioners from all disciplines. Cognitive behavioural therapy (CBT) was developed as a new, effective psychological treatment. 
- Different longitudinal and epidemiological research approaches developed, providing a variety of ways of measuring the presence and impact of mental health problems. Conditions such as anorexia nervosa of childhood, self-harming and neurodevelopmental disorders - autism and ADHD - have been identified. These developments established a significant profile of child and adolescent mental health in professional practice and public awareness.

- Despite attempts to 'shrink the state' in the 1980s, a continuing theme has been the recognition of the hidden yet pervasive traumatic impact of maltreatment many children suffer. The concept has been enlarged through the recognition of adverse childhood experiences (ACEs), adding exposure to family dysfunction and instability. There is a lifespan impact of adversity on mental and physical health and a need for a trauma-informed care approach.

- Fostered by an investment in social inclusion in the 1990 s to the 2000s, multidisciplinary Children and Adolescent Mental Health Services (CAMHS) were established, providing general to highly specialised treatment. Academic units promoted training and research in genetics and neurobiology. The National Institute for Clinical Excellence, later renamed the National Institute for Health and Care Excellence, gathered the growing research information on intervention and recommended best practice.

- The introduction of the Internet in the 1990s has been both beneficial and harmful. The voice of the child as a person can be amplified, including the right to determine their gender. However, the Internet may also provide a route for some people to gratify inappropriate sexual interests in children and young people and to hurt them physically and emotionally. Safety and protection require constant vigilance.

\section{Notes}

1. M. Rutter and J. Stevenson, Developments in child and adolescent psychiatry over the last 50 years. In M. Rutter, D. Bishop and D. Pine et al., eds, Rutter's Child and Adolescent Psychiatry (5th ed.), 1-17. Oxford: Blackwell Science, 2008.

2. T. Judt, Postwar: A History of Europe Since 1945. London: Heinemann, 2005.

3. W. Ll. Parry-Jones, The history of child and adolescent psychiatry: Its present-day relevance. Journal of Child Psychology and Psychiatry (1998) 30: 3-11.

4. E. Rous and A. Clark, Child psychoanalytic psychotherapy in the UK National Health Service: An historical analysis. History of Psychiatry (2009) 20: 442-56, https://doi.org/10.1177/0957154X08338338.

5. D. W. Winnicott, Therapeutic Consultations in Child Psychiatry, London: Hogarth Press, 1971.

6. P. Stratton and J. Lask, The development of systemic family therapy for changing times in the United Kingdom. Contemporary Family Therapy (2013) 35: 257-74, https://doi.org/10.1007/s10591-013-9252-8.

7. L. Courtney, M. A. Benjamin and M. Connor et al., History of cognitive-behavioural therapy (CBT) in youth, Child and Adolescent Psychiatric Clinics of North America (2011) 20: 179-89, https://doi.org/10.1016/j .chc.2011.01.011.

8. J. Bowlby, Maternal Care and Mental Health. Geneva: World Health Organization, 1951.

9. Rutter and Stevenson, Developments in child and adolescent psychiatry over the last 50 years.

10. Ibid.

11. M. Rutter, J. Tizard and K. Whitmore, Education, Health and Behaviour. London: Longmans, 1970.

12. Rutter and Stevenson, Developments in child and adolescent psychiatry over the last 50 years. 
13. Ibid.

14. Ibid.

15. C. H. Kempe, F. N. Silverman and B. F. Steele et al., The battered-child syndrome. JAMA (1962) 181: 17-24.

16. J. Gray, A. Bentovim and P. Milla, The treatment of children and their families where induced illness has been identified. In J. Howarth and B. Lawson, eds, Trust Betrayed Munchausen Syndrome-by-Proxy, Inter-Agency Child Protection and Partnership with Families. London: National Children's Bureau, 1995.

17. N. Parton, Social work, child protection and politics: Some critical and constructive reflections. British Journal of Social Work (2014) 44: 2042-56, https://doi.org/10.1093/bjsw/bcu091.

18. D. Finkelhor, H. Turner, S. Hamby and R. Ormrod, Polyvictimization: Children's Exposure to Multiple Types of Violence, Crime, and Abuse. Office of Juvenile Justice and Delinquency Prevention (OJJDP) bulletin, October 2011, www.ojp.gov/pdffiles1/ojjdp/235504.pdf.

19. A. Bentovim, A. Elton, J. Hildebrand, M. Bentovim and E. Vizard, Child Sexual Abuse within the Family: Assessment and Treatment. Bristol: Wright and Butterworth, 1988.

20. Ibid.

21. Parton, Social work, child protection and politics.

22. C. J. Hobbs and J. M. Wynne, Buggery in childhood: A common syndrome of child abuse. Lancet (1986) 2: 792-6, https://doi.org/10.1016/S0140-6736(86)90310-7.

23. Parton, Social work, child protection and politics.

24. Ibid.

25. Ibid.

26. Rutter and Stevenson, Developments in child and adolescent psychiatry over the last 50 years.

27. D. Di Ceglie and D. Freedman, eds, A Stranger in My Own Body: Atypical Gender Identity and Mental Health. London: Karnac Books, 1998.

28. S. Hamilton, A. Hicks, R. Sayers et al., A User Focused Evaluation of IAPT Services in London. Report for Commissioning Support for London, March 2011.

29. A. Bentovim and W. Kinston, Focal family therapy: Joining systems theory with psychodynamic understanding. In A. S. Gurman and D. P. Kniskern, eds, Handbook of Family Therapy, Vol. 2. New York: Brunner Mazel, 1991.

30. B. F. Chorpita and E. L. Daleiden, Mapping evidence-based treatments for children and adolescents: Application of the distillation and matching model to 615 treatments from 322 randomized trials. Journal of Consulting and Clinical Psychology (2009) 77: 566-79.

31. A. Bentovim and I. Elliott, Targeting abusive parenting and the associated impairment of children. Journal of Clinical Child and Adolescent Psychology (2014) 43: 270-85.

32. D. Skuse, A. Bentovim, J. Hodges et al., Risk factors for development of sexually abusive behaviour in sexually victimised adolescent boys. British Medical Journal (1998) 317: 175-9.

33. V. J. Felitti, R. F. Anda and D. Nordenberg, Relationship of childhood abuse and household dysfunction to many of the leading causes of death in adults: The adverse childhood experiences (ACE) study. American Journal of Preventative Medicine (1998) 14: 245-58.

34. A. Bentovim, A. Cox, L. Bingley Miller and S. Pizzey, Safeguarding Children Living with Trauma and Family Violence: Evidence-Based Approaches to Assessment and Planning Intervention. London: Jessica Kingsley, 2009.

35. P. Greenfield and Z. Yan, Children, adolescents and the Internet: A new field of inquiry in developmental psychology. Development Psychology (2006) 42: 391-4, https://doi.org/10.1037/0012-1649.42.3.391.

36. A. Brown, N. Jago, J. Kerr et al., Call to Keep Children Safe from Sexual Abuse: A Study of the Use and Effects of Stop it Now! UK and Ireland Helpline. London: NatCen Social Research: 2014.

37. Rutter and Stevenson, Developments in child and adolescent psychiatry over the last 50 years. 